\title{
The Contribution of Excision Repair Cross-complementing Group 1 Genotypes to Colorectal Cancer Susceptibility in Taiwan
}

\author{
TE-CHENG YUEH ${ }^{1,2,3^{*}}$, AN-KUO CHOU ${ }^{4 *}$, CHI-LI GONG ${ }^{5 *}$, CHUN-KAI FU $^{1,2}$, \\ JEN-SHENG PEI ${ }^{6}$, MING-HSIEN WU $^{2}$, CHIA-WEN TSAI ${ }^{3}$, WEN-SHIN CHANG ${ }^{3}$, \\ CHIEH-LUN HSIAO ${ }^{3}$, SHIOU-TING YEN ${ }^{3}$, HSIN-TING LI ${ }^{3}$ and DA-TIAN BAU ${ }^{1,3,7}$ \\ ${ }^{I}$ Graduate Institute of Biomedical Sciences, China Medical University, Taichung, Taiwan, R.O.C.; \\ ${ }^{2}$ Taichung Armed Forces General Hospital, Taichung, Taiwan, R.O.C.; \\ ${ }^{3}$ Terry Fox Cancer Research Laboratory, Department of Medical Research, \\ China Medical University Hospital, Taichung, Taiwan, R.O.C.; \\ ${ }^{4}$ Department of Anesthesiology, China Medical University Hospital, Taichung, Taiwan, R.O.C.; \\ ${ }^{5}$ Department of Physiology, China Medical University, Taichung, Taiwan, R.O.C.; \\ ${ }^{6}$ Department of Pediatrics, Taoyuan General Hospital, Ministry of Health and Welfare, Taoyuan, Taiwan, R.O.C.; \\ ${ }^{7}$ Department of Bioinformatics and Medical Engineering, Asia University, Taichung, Taiwan, R.O.C.
}

\begin{abstract}
Aim: To evaluate the contribution of ERCC1 rs11615 and rs3212986 genotypes regarding the risk of colorectal cancer (CRC) in Taiwan. Materials and Methods: In this case-control study, ERCC1 rs11615 and rs3212986 genotypes and their interaction with consumption of cigarettes and alcohol in determining $C R C$ risk were investigated among 362 CRC patients and 362 age- and gender-matched healthy controls. Results: The percentages of CC, CT and TT for ERCC1 rs11615 genotype were $44.2 \%, 36.2 \%$ and $19.6 \%$ in the CRC group and $49.7 \%, 38.4 \%$ and $11.9 \%$ in the control group, respectively ( $p$ for trend $=0.0158$ ). The allelic frequency distribution analysis showed that the variant $T$ allele of ERCC1 rs 11615 conferred increased CRC susceptibility to the wild-type $C$ allele (odds ratio $(O R)=1.34,95 \%$ confidence interval $(C I)=1.08-1.67, p=0.0079)$. As for the gene-lifestyle interaction, there were obvious joint effects of ERCC1 rs 11615 genotype on the risk of CRC among ever smokers and alcohol drinkers, but not non-smokers or non-drinkers. There is a positive correlation of ERCC1 rs11615 genotype with lymph
\end{abstract}

\footnotetext{
*These Authors contributed equally to this study.

Correspondence to: Da-Tian Bau, Terry Fox Cancer Research Laboratory, China Medical University Hospital, 2 Yuh-Der Road, Taichung, 404 Taiwan, R.O.C. Tel: +886 422052121 (Ext. 7534), e-mail:datian@mail.cmuh.org.tw; artbau2@gmail.com
}

Key Words: Colorectal cancer, ERCC1, genotype, polymorphism, Taiwan. node metastasis, but not other CRC prognosis, including tumor size and location. Conclusion: ERCC1 rs11615 T allele serves as a predictive marker for CRC risk and future studies with larger samples and functional evaluation are warranted to validate these findings.

Statistically, nearly one million cases of colorectal cancer (CRC) diagnoses worldwide each year and the incidence, as well as age-adjusted mortality of CRC, keep on increasing in recent years (1). In Taiwan, the incidence and mortality of CRC has occupied the first and third places among the common types of cancer for many years and the high incidence has been proposed to be closely associated with dietary changes to Western food style and a decreased consumption of dietary fiber or grain-made foods. Etiological studies have attributed more than $85 \%$ of CRC to risk environmental factors (1-3), particularly meat consumption, cigarette smoking, exposure to carcinogenic aromatic amines, such as arylamines and heterocyclic amines $(4,5)$. About $15-20 \%$ of CRC cases are with strong familial history of cancer that have interested the epidemiologists to figure out additional inherited susceptibility factors (6-8). In Taiwan, although specific biomarkers for CRC prediction and detection have keeping on being reported in recent years (9-16), the genomic susceptibility of CRC and the interactions among the genomic and environmental risk factors are mostly unknown.

Our genome is regularly and frequently damaged by various kinds of endogenous and exogenous mutagens and the DNA repair systems play a vital role in protecting our genome from 
irreversible mutations leading to carcinogenesis, among which the nucleotide excision repair (NER) pathway is one of the nuclear DNA repair systems used in correcting subtle DNA lesions and bulky DNA damage $(17,18)$. Among the DNA repair proteins involved in NER, excision repair crosscomplementing group 1 (ERCC 1 ) is located on chromosome $19 q 13.3$ and participates as the central rate-limiting enzyme in the multistep NER process. For instance, Shirota and his colleagues have suggested that down-regulation of ERCC1 expression is associated with increased chemotherapeutic sensitivity and, thus, considered a predictive marker for CRC patients receiving combination of oxaliplatin and fluorouracil chemotherapy (19). In addition, Huang and his colleagues reported that A2251C variants of ERCC2 were associated with increased risk of early relapse in CRC (20). In the literature, several single-nucleotide polymorphisms (SNPs) of ERCC1 have been well identified, of which ERCC1 rs11615 and rs3212986 SNPs (Asn118Asn and C8092A) both have transcriptional moderating effects on their mRNA expression (21). Given the role of ERCCl in genomic stability maintenance and carcinogenesis progression, we hypothesized that genomic variations in the ERCCl gene may determine the individual susceptibility of Taiwanese to CRC. Therefore, we conducted a hospital-based case-control study to investigate the genotypes of ERCCl firstly among Taiwanese and examine the association of ERCCl genotypes with the risk of $\mathrm{CRC}$ in a Taiwanese population.

\section{Materials and Methods}

Investigated population. The investigated population included 724 subjects (362 CRC patients and 362 healthy controls). Patients diagnosed with CRC were recruited at the outpatient clinics of general surgery between 2002 and 2008 at the China Medical University Hospital, Taichung, Taiwan, Republic of China, by the team of Drs. Jeng LB and Yang MD. The clinical characteristics of patients, including histological details, were all graded and defined by expert surgeons $(9,10,13,16)$. All participants have completed a selfadministered questionnaire and provided a 5-ml sample of peripheral blood for genotyping work. An equal number of non-cancer healthy volunteers $(n=362)$ were selected as controls by matching for age, gender and some indulgences after initial random sampling from the Health Examination Cohort of the Hospital with the help of colleagues in the Department of Family Medicine. The exclusion criteria of the control group included previous malignancy, metastasized cancer from other or unknown origin and any familial or genetic diseases. This study was approved by the Institutional Review Board of the China Medical University Hospital (IRB project identification coding number: DMR99-IRB-108) and written informed consent was obtained from all participants with the help of Tissue Bank of China Medical University Hospital. The selected patients' characteristics, extracted from personal questionnaires, are summarized in Table I.

Genotyping conditions. Genomic DNA from peripheral blood leucocytes of each investigated subject was prepared applying the QIAamp Blood Mini Kit (Blossom, Taipei, Taiwan) and stored
Table I. Summary of selected data of the 362 patients with colorectal cancer and 362 matched non-cancer healthy controls.

\begin{tabular}{|c|c|c|c|c|c|}
\hline \multirow[t]{2}{*}{ Characteristic } & \multicolumn{2}{|c|}{ Controls $(n=362)$} & \multicolumn{2}{|c|}{ Cases $(n=362)$} & \multirow[t]{2}{*}{$p$-Value } \\
\hline & $\mathrm{n}$ & $\%$ & $\mathrm{n}$ & $\%$ & \\
\hline \multicolumn{6}{|l|}{ Age (years) } \\
\hline$\leq 60$ & 93 & $25.7 \%$ & 95 & $26.2 \%$ & 0.8654 \\
\hline$>60$ & 269 & $74.3 \%$ & 267 & $73.8 \%$ & \\
\hline \multicolumn{6}{|l|}{ Gender } \\
\hline Male & 209 & $57.7 \%$ & 203 & $56.1 \%$ & 0.6525 \\
\hline Female & 153 & $42.3 \%$ & 159 & $43.9 \%$ & \\
\hline \multicolumn{6}{|c|}{ Tumor size $(\mathrm{cm})$} \\
\hline$<5$ & & & 195 & $53.9 \%$ & \\
\hline$\geq 5$ & & & 167 & $46.1 \%$ & \\
\hline \multicolumn{6}{|l|}{ Location } \\
\hline Colon & & & 257 & $71.0 \%$ & \\
\hline Rectum & & & 105 & $29.0 \%$ & \\
\hline \multicolumn{6}{|c|}{ Lymph node metastasis } \\
\hline Negative & & & 210 & $58.0 \%$ & \\
\hline Positive & & & 152 & $42.0 \%$ & \\
\hline
\end{tabular}

SD, Standard deviation; abased on Chi-square test without Yates' correction.

at $-80^{\circ} \mathrm{C}$ until processed as per our recent publications $(9,22,23)$. The methodology for ERCC1 rs11615 and rs3212986 genotyping, including the designing of the specific primers and the selection of restriction enzymes, were firstly designed in our lab. Briefly, the sequences for forward and reverse primer pairs for ERCC1 rs11615 were 5'-TTAGGAGGAGAGAGAAGCTG-3' and 5'-GGCTTCTC ATAGAACAGTCC-3', respectively. The sequences for forward and reverse primer pairs for ERCC1 rs3212986 were 5'-AGGC TGTTTGATGTCCTGCA-3' and 5'-AGAGGAAGAAGCAGAGT CAG-3', respectively. The polymerase chain reaction (PCR) cycling conditions were set as one cycle at $94^{\circ} \mathrm{C}$ for $5 \mathrm{~min} ; 35$ cycles of $94^{\circ} \mathrm{C}$ for $30 \mathrm{~s}, 58^{\circ} \mathrm{C}$ for $30 \mathrm{~s}$ and $72^{\circ} \mathrm{C}$ for $30 \mathrm{~s}$; and a final extension step at $72^{\circ} \mathrm{C}$ for $10 \mathrm{~min}$. After PCR amplification, the PCR products were subject to the digestion by $B s r D$ I and MboI I restriction endonucleases, respectively, for $2 \mathrm{~h}$ at $37^{\circ} \mathrm{C}$ and separation via $3 \%$ agarose gel electrophoresis for $25 \mathrm{~min}$. The ERCC1 rs 11615 genotypes were identified as homozygous $\mathrm{C} / \mathrm{C}$ with 393-bp product, heterozygous C/T with 393-, 228- and 165-bp products, as well as homozygous T/T with 228 - and 165 -bp products, respectively. The ERCC1 rs3212986 genotypes were identified as homozygous G/G with 367-bp product, heterozygous G/T with 367-, 233- and 134-bp products, as well as homozygous T/T with 233- and 134-bp products, respectively. All the genotypic processing was repeated by two researchers independently and blindly; all the genotyping results were $100 \%$ concordant.

Statistical analyses. The Student's $t$-test was applied for the comparison of ages between the CRC cases and the control groups. Pearson's Chi-square test was applied to compare the distribution of the ERCC1 genotypes among the subgroups. The associations between ERCC1 genotypes and CRC risk were estimated by computing odds ratios (ORs) and their $95 \%$ confidence intervals (CIs) 
Table II. Excision repair cross-complementing group 1 (ERCC1) genotypes among the 362 patients with colorectal cancer and 362 matched healthy controls.

\begin{tabular}{|c|c|c|c|c|c|c|}
\hline \multirow[t]{2}{*}{ Genotype } & \multicolumn{2}{|c|}{ Controls } & \multicolumn{2}{|c|}{ Patients } & \multirow[t]{2}{*}{ OR $(95 \% \mathrm{CI})$} & \multirow[t]{2}{*}{$p$-Value ${ }^{\mathrm{a}}$} \\
\hline & $\mathrm{n}$ & $\%$ & $\mathrm{n}$ & $\%$ & & \\
\hline \multicolumn{7}{|l|}{ rs11615 } \\
\hline $\mathrm{CC}$ & 180 & $49.7 \%$ & 160 & $44.2 \%$ & 1.00 (Reference) & \\
\hline $\mathrm{CT}$ & 139 & $38.4 \%$ & 131 & $36.2 \%$ & $1.06(0.77-1.46)$ & 0.7200 \\
\hline $\mathrm{TT}$ & 43 & $11.9 \%$ & 71 & $19.6 \%$ & $1.86(1.20-2.87)$ & $0.0049 *$ \\
\hline ptrend & & & & & & $0.0158 *$ \\
\hline \multicolumn{7}{|c|}{ Carrier comparison } \\
\hline $\mathrm{CC}+\mathrm{CT}$ & 319 & $88.1 \%$ & 291 & $80.4 \%$ & 1.00 (Reference) & \\
\hline TT & 43 & $11.9 \%$ & 71 & $19.6 \%$ & $1.81(1.20-2.73)$ & $0.0043^{*}$ \\
\hline $\mathrm{CC}$ & 180 & $49.7 \%$ & 160 & $44.2 \%$ & 1.00 (Reference) & \\
\hline $\mathrm{CT}+\mathrm{TT}$ & 182 & $50.3 \%$ & 202 & $55.8 \%$ & $1.25(0.93-1.67)$ & 0.1364 \\
\hline \multicolumn{7}{|l|}{ rs3212986 } \\
\hline $\mathrm{TT}$ & 177 & $48.9 \%$ & 181 & $50.0 \%$ & 1.00 (Reference) & \\
\hline GT & 139 & $38.4 \%$ & 133 & $36.7 \%$ & $0.94(0.68-1.28)$ & 0.6795 \\
\hline GG & 46 & $12.7 \%$ & 48 & $13.3 \%$ & $1.02(0.65-1.61)$ & 0.9305 \\
\hline ptrend & & & & & & 0.8960 \\
\hline \multicolumn{7}{|c|}{ Carrier comparison } \\
\hline $\mathrm{TT}+\mathrm{GT}$ & 316 & $87.3 \%$ & 314 & $86.7 \%$ & 1.00 (Reference) & \\
\hline GG & 46 & $12.7 \%$ & 48 & $13.3 \%$ & $1.05(0.68-1.62)$ & 0.8250 \\
\hline TT & 177 & $48.9 \%$ & 181 & $50.0 \%$ & 1.00 (Reference) & \\
\hline $\mathrm{GT}+\mathrm{GG}$ & 185 & $51.1 \%$ & 181 & $50.0 \%$ & $0.96(0.71-1.28)$ & 0.7662 \\
\hline
\end{tabular}

aBased on chi-square test without Yates's correction; *statistically significant; OR, odds ratio; CI, confidence interval.

from logistic regression analysis. Statistically, any difference at $p<0.05$ was taken as significant between the two groups compared.

\section{Results}

The frequency distributions of selected characters, including age and gender for the 362 CRC patients in the case group and 362 non-cancer healthy subjects in the control group, are summarized and compared in Table I. In addition, tumor size, location,and lymph node metastasis status are also summarized in Table I. Since we applied frequency matching to recruit non-cancer healthy subjects as controls, there was no difference in the distributions of age and gender between the control and case groups $(p=0.8654$ and 0.6525 , respectively) (Table I). The patients with tumor size $<5 \mathrm{~cm}$ and $\geq 5 \mathrm{~cm}$ were 195 and 167 , respectively. The patients with tumor location at colon and rectum were 257 and 105 , respectively. The patients with and without lymph node metastasis were 152 and 210, respectively (Table I).

The distributions of the ERCC1 rs11615 and rs3212986 genotypes among the 326 non-cancer controls and the 326 CRC patients are presented and statistically analyzed in Table II. The results showed that the genotypes of ERCCI rs11615 were differently distributed between case and control groups ( $\mathrm{p}$ for trend=0.0158) (Table II). In detail, the ERCC1 rs11615 homozygous TT, but not the heterozygous $\mathrm{CT}$, was associated with $\mathrm{CRC}$ risk, compared with wild-type $\mathrm{CC}$ genotype $(\mathrm{OR}=1.86$ and $1.06,95 \% \mathrm{CI}=1.20-2.87$ and $0.77-1.46, p=0.0049$ and 0.7200 , respectively; Table II). In the recessive model, there was a positive association between the TT genotype of ERCC1 rs11615 and CRC risk, compared with $\mathrm{CC}+\mathrm{CT}$ genotypes $(\mathrm{OR}=1.81,95 \% \mathrm{CI}=1.20-2.73$, $p=0.0043$, Table II). The genotypes of ERCC1 rs3212986 were not differently distributed between case and control groups in all models (Table II).

To confirm the results in Table II, analysis of allelic frequency distribution for the ERCC1 rs11615 and rs3212986 was further conducted and the results are presented in Table III. Supporting the findings that genotype of ERCC1 rs11615 was associated with CRC risk, the variant allele $\mathrm{T}$ was found at $37.7 \%$ in the case group, significantly higher than that of $31.1 \%$ in the control group $(\mathrm{OR}=1.34$, 95\% CI=1.08-1.67, $p=0.0079$ ). At the same time, there was no significant difference in the allelic frequencies of ERCC1 rs3212986 between the case and control groups (Table III).

Since smoking and alcohol drinking habits are well-known risk factors for CRC in Taiwan, we were interested in investigating the interactions between the genotype of ERCC1 
Table III. Distribution of allelic frequencies for excision repair cross-complementing group 1 (ERCC1) among the 362 patients with colorectal cancer and 362 matched healthy controls.

\begin{tabular}{|c|c|c|c|c|c|c|}
\hline Allele & Controls, $\mathrm{n}$ & $\%$ & Patients, $\mathrm{n}$ & $\%$ & OR $(95 \% \mathrm{CI})$ & $p$-Value ${ }^{\mathrm{a}}$ \\
\hline \multicolumn{7}{|c|}{ rs11615 } \\
\hline $\mathrm{C}$ & 499 & $68.9 \%$ & 451 & $62.3 \%$ & 1.00 (Reference) & \\
\hline $\mathrm{T}$ & 225 & $31.1 \%$ & 273 & $37.7 \%$ & $1.34(1.08-1.67)$ & $0.0079 *$ \\
\hline \multicolumn{7}{|c|}{ rs3212986 } \\
\hline G & 493 & $68.1 \%$ & 495 & $68.4 \%$ & 1.00 (Reference) & \\
\hline $\mathrm{T}$ & 231 & $31.9 \%$ & 229 & $31.6 \%$ & $0.99(0.79-1.23)$ & 0.9101 \\
\hline
\end{tabular}

aBased on chi-square test without Yates's correction; *statistically significant.

Table IV. Odds ratios for excision repair cross-complementing group 1 (ERCC1) rs11615 genotype and colorectal cancer after stratification by smoking status.

\begin{tabular}{|c|c|c|c|c|c|c|c|c|c|c|}
\hline \multirow[t]{2}{*}{ Genotype } & \multicolumn{2}{|c|}{ Non-smokers, $\mathrm{n}$} & \multirow{2}{*}{$\begin{array}{c}\text { OR } \\
(95 \% \mathrm{CI})^{\mathrm{a}}\end{array}$} & \multirow{2}{*}{$\begin{array}{c}\mathrm{aOR} \\
(95 \% \mathrm{CI})^{\mathrm{b}}\end{array}$} & \multirow[t]{2}{*}{$p$-Value } & \multicolumn{2}{|c|}{ Smokers, $\mathrm{n}$} & \multirow{2}{*}{$\begin{array}{c}\text { OR } \\
(95 \% \mathrm{CI})^{\mathrm{a}}\end{array}$} & \multirow{2}{*}{$\begin{array}{c}\mathrm{aOR} \\
(95 \% \mathrm{CI})^{\mathrm{b}}\end{array}$} & \multirow[t]{2}{*}{$p$-Value } \\
\hline & Controls & Cases & & & & Controls & Cases & & & \\
\hline $\mathrm{CC}$ & 137 & 126 & 1.00 (ref) & 1.00 (ref) & & 43 & 34 & 1.00 (ref) & 1.00 (ref) & \\
\hline $\mathrm{CT}$ & 105 & 101 & $1.05(0.73-1.51)$ & $1.07(0.75-1.55)$ & 0.8096 & 34 & 30 & $1.12(0.57-2.17)$ & $1.27(0.61-2.31)$ & 0.7468 \\
\hline TT & 36 & 44 & $1.33(0.80-2.20)$ & $1.34(0.85-2.05)$ & 0.2666 & 7 & 27 & $4.88(1.90-12.55)$ & $4.41(1.94-11.53)$ & $0.0006^{*}$ \\
\hline Total & 278 & 271 & & & & 84 & 91 & & & \\
\hline
\end{tabular}

aBy multivariate logistic regression analysis; by multivariate logistic regression analysis after adjusted of age, gender and alcohol drinking status; *statistically significant; CI, confidence interval; aOR, adjusted odds ratio.

Table V. Odds ratios for excision repair cross-complementing group 1 (ERCC1) rs11615 genotype and colorectal cancer after stratification by alcohol drinking status.

\begin{tabular}{|c|c|c|c|c|c|c|c|c|c|c|}
\hline \multirow[t]{2}{*}{ Genotype } & \multicolumn{2}{|c|}{ Non-drinker, $\mathrm{n}$} & \multirow{2}{*}{$\begin{array}{c}\text { OR } \\
(95 \% \mathrm{CI})^{\mathrm{a}}\end{array}$} & \multirow{2}{*}{$\begin{array}{c}\mathrm{aOR} \\
(95 \% \mathrm{CI})^{\mathrm{b}}\end{array}$} & \multirow[t]{2}{*}{$p$-Value } & \multicolumn{2}{|c|}{ Drinkers, $\mathrm{n}$} & \multirow{2}{*}{$\begin{array}{c}\text { OR } \\
(95 \% \mathrm{CI})^{\mathrm{a}}\end{array}$} & \multirow{2}{*}{$\begin{array}{c}\mathrm{aOR} \\
(95 \% \mathrm{CI})^{\mathrm{b}}\end{array}$} & \multirow[t]{2}{*}{$p$-Value } \\
\hline & Controls & Cases & & & & Controls & Cases & & & \\
\hline $\mathrm{CC}$ & 155 & 146 & 1.00 (ref) & 1.00 (ref) & & 25 & 14 & 1.00 (ref) & 1.00 (ref) & \\
\hline $\mathrm{CT}$ & 118 & 117 & $1.05(0.75-1.48)$ & $1.11(0.79-1.49)$ & 0.7683 & 21 & 14 & $1.19(0.46-3.05)$ & $1.24(0.47-3.21)$ & 0.7164 \\
\hline TT & 38 & 55 & $1.54(0.96-2.46)$ & $1.48(0.94-2.54)$ & 0.0729 & 5 & 16 & $5.71(1.72-18.94)$ & $5.46(1.68-17.87)$ & $0.0029^{*}$ \\
\hline Total & 311 & 318 & & & & 51 & 44 & & & \\
\hline
\end{tabular}

aBy multivariate logistic regression analysis; by multivariate logistic regression analysis after adjusted of age, gender and smoking status; *statistically significant; CI, confidence interval; aOR, adjusted odds ratio.

rs11615 and personal cigarette smoking and alcohol drinking habits. Among smokers, those with TT genotype at ERCC1 rs11615 were at 4.88 -fold odds of having CRC (95\% CI=1.90$12.55, p=0.0006)$ conferring a risky effect, while this was not the case for non-smokers (Table IV). After adjusting for age, gender and alcohol drinking status, statistical significance still existed at a similar level $(\mathrm{OR}=4.41,95 \% \mathrm{CI}=1.94-11.53$, Table IV). On the other hand, among alcohol drinkers, those with TT genotype at ERCC1 rs11615 were at 5.71-fold odds of having CRC (95\% CI=1.72-18.94, $p=0.0029)$ conferring a risky effect, while this was not the case for non-drinkers (Table V). After adjusting for age, gender and smoking status, results were equally significant $(\mathrm{OR}=5.46,95 \% \mathrm{CI}=1.68-17.87$, Table V).

The correlations between genotypes of ERCC1 rs11615 and clinicopathological features of 362 CRC patients were analyzed and summarized in Table VI. No statistically 
Table VI. Correlation between excision repair cross-complementing group 1 rs11615 genotypes and clinicopathological properties of 362 colorectal cancer patients.

\begin{tabular}{|c|c|c|c|c|c|}
\hline \multirow[t]{2}{*}{ Characteristics } & \multirow[t]{2}{*}{ Case number } & \multicolumn{3}{|c|}{ Genotypes } & \multirow[t]{2}{*}{$p$-Value ${ }^{\mathrm{a}}$} \\
\hline & & $\mathrm{CC}(\%)$ & $\mathrm{CT}(\%)$ & TT $(\%)$ & \\
\hline \multicolumn{6}{|l|}{ Age (years) } \\
\hline$\leq 60$ & 95 & $44(46.3)$ & $35(36.8)$ & $16(16.9)$ & \\
\hline$>60$ & 267 & $116(43.4)$ & $96(36.0)$ & $55(20.6)$ & 0.7225 \\
\hline \multicolumn{6}{|l|}{ Gender } \\
\hline Male & 203 & $89(43.8)$ & $70(34.5)$ & $44(21.7)$ & \\
\hline Female & 159 & $71(44.6)$ & $61(38.4)$ & $27(17.0)$ & 0.5000 \\
\hline \multicolumn{6}{|l|}{ Tumor size } \\
\hline$<5 \mathrm{~cm}$ & 195 & $85(43.6)$ & $71(36.4)$ & $39(20.0)$ & \\
\hline$\geq 5 \mathrm{~cm}$ & 167 & $75(44.9)$ & $60(35.9)$ & $32(19.2)$ & 0.9639 \\
\hline \multicolumn{6}{|l|}{ Location } \\
\hline Colon & 257 & $115(44.7)$ & $92(35.8)$ & $50(19.5)$ & \\
\hline Rectum & 105 & $45(42.9)$ & $39(37.1)$ & $21(20.0)$ & 0.9471 \\
\hline \multicolumn{6}{|c|}{ Lymph node metastasis } \\
\hline Negative & 210 & $106(50.5)$ & $73(34.8)$ & $31(14.7)$ & \\
\hline Positive & 152 & $54(35.5)$ & $58(38.2)$ & $40(26.3)$ & $0.0047^{*}$ \\
\hline
\end{tabular}

aBased on chi-square test without Yates's correction; *statistically significant.

significant correlation was observed between ERCC1 rs11615 genotypic distributions and age, gender, tumor size or location (all $p>0.05$ ). The most important finding was that the ERCC1 rs11615 genotype was associated with lymph node metastasis $(p=0.0047)$ (Table VI).

\section{Discussion}

In the literature, genotypes of DNA repair genes may be associated with prognosis of chemotherapy in cancer patients. The DNA repair system plays an important role in maintaining the integrity of human genome that controls the homeostasis of cellular functions via the reversal of all types of DNA damage due to variety of factors, including cancer therapeutic agents. Therefore, overall DNA repair capacity may greatly contribute not only to cancer susceptibility but, also, prognosis (24). ERCCl plays a central role in NER pathway and is responsible for a major part of routine DNA damage (25). The ERCCl genotypes of rs11615 and rs3212986 may provide predictive information of platinumbased chemotherapy of advanced gastric cancer (26), advanced non-small cell lung cancer (27), testicular germ cell tumors (28), advanced epithelial ovarian cancer (29) and esophageal cancer (30). Molecular studies showed that ERCC1 rs11615 $\mathrm{T}$ allele is associated with diminished mRNA and protein expression levels but represents, however, a controversial predictive marker for cancer therapy (31-35). In the initial steps of carcinogenesis, the defects in DNA repair capacity of cells determined by variant $E R C C l$ genotypes may also contribute to increased cancer susceptibility. In the current work, we found that ERCC1 rs11615 TT genotype is associated with 1.86-fold enhanced CRC risk (Table II), which is further elevated to 4.88 -fold odds of having CRC among smokers and 5.71-fold odds among alcohol drinkers (Tables IV and V). This is the first study to reveal joint effects between ERCC1 rs 11615 genotypes with cigarette smoking and alcohol drinking habits on the susceptibility to CRC.

Despite our efforts to conduct an accurate and comprehensive genotyping work and related analysis, there are some limitations that should be noted. Firstly, the lack of recorded follow-ups limited the analysis of the correlation of prognosis indexes, such as survival rates. Table VI only provides evidence for the ERCC1 rs11615 genotype that did not contribute to the prediction of tumor size, location and metastasis. Secondly, lack of tumor and non-tumor samples limited the study of differential expression of ERCC1 mRNA and protein levels among the subjects, in addition to the inter-individual difference of the CRC patients. Further molecular investigations of the genotype-phenotype correlation may help in understanding the contribution of ERCCl genotypes to not only overall DNA repair capacity but, also, personal susceptibility to CRC and/or other types of cancer. Thirdly, the relatively small sample size, especially in subgroup analysis, such as those in Tables IV and V, may have caused some bias and reduced the statistic power of our estimates.

In conclusion, this study provides evidence that the $\mathrm{T}$ allele at ERCC1 rs11615 may interact with smoking and alcohol drinking status to determine personal susceptibility to CRC; 
however, more research should be conducted to reveal the detailed alteration of DNA repair capacity in relation to CRC susceptibility and prognosis of chemotherapy.

\section{Acknowledgements}

The Authors declare no conflict of interest in regard to this study. They also appreciate the Tissue-bank of China Medical University Hospital for their excellent technical assistance and all the subjects, doctors, nurses and colleagues. This study was supported mainly by the Taichung Armed Forces General Hospital 106A14 to Dr. Yueh and partially by research grant from Taiwan Ministry of Health and Welfare Clinical Trial and Research Center of Excellence (MOHW106-TDU-B-212-113004).

\section{References}

1 Torre LA, Bray F, Siegel RL, Ferlay J, Lortet-Tieulent J and Jemal A: Global cancer statistics, 2012. CA Cancer J Clin 65: 87-108, 2015.

2 Jemal A, Siegel R, Xu J and Ward E: Cancer statistics, 2010. CA Cancer J Clin 60: 277-300, 2010.

3 Jemal A, Bray F, Center MM, Ferlay J, Ward E and Forman D: Global cancer statistics. CA Cancer J Clin 61: 69-90, 2011.

4 Nagini S: Carcinoma of the stomach: A review of epidemiology, pathogenesis, molecular genetics and chemoprevention. World J Gastrointest Oncol 4: 156-169, 2012.

5 Jayasurya R, Sathyan KM, Lakshminarayanan K, Abraham T, Nalinakumari KR, Abraham EK, Nair MK and Kannan S: Phenotypic alterations in $\mathrm{Rb}$ pathway have more prognostic influence than p53 pathway proteins in oral carcinoma. Mod Pathol 18: 1056-1066, 2005.

6 Butterworth AS, Higgins JP and Pharoah P: Relative and absolute risk of colorectal cancer for individuals with a family history: A meta-analysis. Eur J Cancer 42: 216-227, 2006.

7 Houlston RS and Tomlinson IP: Polymorphisms and colorectal tumor risk. Gastroenterology 121: 282-301, 2001.

8 Rasool S, Rasool V, Naqvi T, Ganai BA and Shah BA: Genetic unraveling of colorectal cancer. Tumour Biol 35: 5067-5082, 2014.

9 Chang WS, Yueh TC, Tsai CW, Ji HX, Wu CN, Wang SC, Lai YL, Hsu SW, Hsieh MH, Hsiao CL, Hung YW, Shih TC and Bau DT: Contribution of DNA repair Xeroderma Pigmentosum Group D genotypes to colorectal cancer risk in Taiwan. Anticancer Res 36: 1657-1663, 2016.

10 Huang CY, Tsai CW, Hsu CM, Chang WS, Shui HA and Bau DT: The significant association of CCND1 genotypes with colorectal cancer in Taiwan. Tumour Biol 36: 6533-6540, 2015.

11 Yang MD, Tsai CW, Chang WS, Tsou YA, Wu CN and Bau DT: Predictive role of XRCC5/XRCC6 genotypes in digestive system cancers. World J Gastrointest Oncol 3: 175-181, 2011.

12 Yang MD, Tsai RY, Liu CS, Chang CH, Wang HC, Tsou YA, Wang CH, Lin CC, Shyue SK and Bau DT: Association of Caveolin-1 polymorphisms with colorectal cancer susceptibility in Taiwan. World J Gastrointest Oncol 2: 326-331, 2010.

13 Bau DT, Yang MD, Tsou YA, Lin SS, Wu CN, Hsieh HH, Wang RF, Tsai CW, Chang WS, Hsieh HM, Sun SS and Tsai RY: Colorectal cancer and genetic polymorphism of DNA doublestrand break repair gene XRCC4 in Taiwan. Anticancer Res 30: 2727-2730, 2010
14 Yeh YS, Tsai HL, Huang CW, Wang JH, Lin YW, Tang HC, Sung YC, Wu CC, Lu CY and Wang JY: Prospective analysis of UGT1A1 promoter polymorphism for irinotecan dose escalation in metastatic colorectal cancer patients treated with bevacizumab plus FOLFIRI as the first-line setting: study protocol for a randomized controlled trial. Trials 17: 46, 2016.

15 Shi MD, Chen JH, Sung HT, Lee JS, Tsai LY and Lin HH: CXCL12-G801A polymorphism modulates risk of colorectal cancer in Taiwan. Arch Med Sci 9: 999-1005, 2013.

16 Yang MD, Hsu YM, Kuo YS, Chen HS, Chang CL, Wu CN, Chang $\mathrm{CH}$, Liao YM, Wang HC, Wang MF and Bau DT: Significant association of Ku80 single nucleotide polymorphisms with colorectal cancer susceptibility in Central Taiwan. Anticancer Res 29: 2239-2242, 2009.

17 De Silva IU, McHugh PJ, Clingen PH and Hartley JA: Defining the roles of nucleotide excision repair and recombination in the repair of DNA interstrand cross-links in mammalian cells. Mol Cell Biol 20: 7980-7990, 2000.

18 Braithwaite E, Wu X and Wang Z: Repair of DNA lesions: mechanisms and relative repair efficiencies. Mutat Res 424: 207219, 1999.

19 Shirota Y, Stoehlmacher J, Brabender J, Xiong YP, Uetake H, Danenberg KD, Groshen S, Tsao-Wei DD, Danenberg PV and Lenz HJ: ERCC1 and thymidylate synthase mRNA levels predict survival for colorectal cancer patients receiving combination oxaliplatin and fluorouracil chemotherapy. J Clin Oncol 19: 4298-4304, 2001.

20 Huang MY, Fang WY, Lee SC, Cheng TL, Wang JY and Lin SR: ERCC2 2251A $>$ C genetic polymorphism was highly correlated with early relapse in high-risk stage II and stage III colorectal cancer patients: A preliminary study. BMC Cancer 8: 50, 2008.

21 Yu JJ, Lee KB, Mu C, Li Q, Abernathy TV, Bostick-Bruton F and Reed E: Comparison of two human ovarian carcinoma cell lines (A2780/CP70 and MCAS) that are equally resistant to platinum, but differ at codon 118 of the ERCC1 gene. Int $\mathbf{J}$ Oncol 16: 555-560, 2000.

22 Chang WS, Liao CH, Tsai CW, Hu PS, Wu HC, Hsu SW, Hsiao CL, Hsu CH, Hung YW and Bau DT: Association of enhancer of Zeste 2 (EZH2) genotypes with bladder cancer risk in Taiwan. Anticancer Res 36: 4509-4514, 2016.

23 Chang WS, Liao CH, Tsai CW, Hu PS, Wu HC, Hsu SW, Ji HX, Hsiao CL and Bau DT: The role of IL-10 promoter polymorphisms in renal cell carcinoma. Anticancer Res 36: 2205-2209, 2016.

24 Li Y, Liu Z, Liu H, Wang LE, Tan D, Ajani JA and Wei QY: ERCC1 and ERCC2 variants predict survival in gastric cancer patients. PLoS One 8: e71994, 2013.

25 Wang Z, Chen JQ, Liu JL, Qin XG and Huang Y: Polymorphisms in ERCC1, GSTs, TS and MTHFR predict clinical outcomes of gastric cancer patients treated with platinum/5-Fu-based chemotherapy: A systematic review. BMC Gastroenterol 12: 137, 2012.

26 Mokmeli S, Tehrani GA, Zamiri RE and Bahrami T: Investigating the frequency of the ERCC1 gene C8092A polymorphism in Iranian patients with advanced gastric cancer receiving platinum-based chemotherapy. Asian Pac J Cancer Prev 17: 1369-1372, 2016.

27 Zhou C, Ren S, Zhou S, Zhang L, Su C, Zhang Z, Deng Q and Zhang J: Predictive effects of ERCC1 and XRCC3 SNP on efficacy of platinum-based chemotherapy in advanced NSCLC patients. Jpn J Clin Oncol 40: 954-960, 2010. 
28 Mendoza J, Martinez J, Hernandez C, Perez-Montiel D, Castro C, Fabian-Morales E, Santibanez M, Gonzalez-Barrios R, Diaz-Chavez J, Andonegui MA, Reynoso N, Onate LF, Jimenez MA, Nunez M, Dyer R and Herrera LA: Association between ERCC1 and XPA expression and polymorphisms and the response to cisplatin in testicular germ cell tumours. Br J Cancer 109: 68-75, 2013.

29 Moxley KM, Benbrook DM, Queimado L, Zuna RE, Thompson D, McCumber M, Premkumar P, Thavathiru E, Hines L and Moore KN: The role of single nucleotide polymorphisms of the ERCC1 and MMS19 genes in predicting platinum-sensitivity, progression-free and overall survival in advanced epithelial ovarian cancer. Gynecol Oncol 130: 377-382, 2013.

30 Rumiato E, Cavallin F, Boldrin E, Cagol M, Alfieri R, Basso D, Castoro C, Ancona E, Amadori A, Ruol A and Saggioro D: ERCC1 C8092A (rs3212986) polymorphism as a predictive marker in esophageal cancer patients treated with cisplatin/5-FU-based neoadjuvant therapy. Pharmacogenet Genomics 23: 597-604, 2013.

31 van Huis-Tanja LH, Kweekel DM, Lu X, Franken K, Koopman M, Gelderblom H, Antonini NF, Punt CJ, Guchelaar HJ and van der Straaten T: Excision repair cross-complementation group 1 (ERCC1) C118T SNP does not affect cellular response to oxaliplatin. Mutat Res 759: 37-44, 2014.

32 Zaanan A, Dalban C, Emile JF, Blons H, Flejou JF, Goumard C, Istanbullu M, Calmel C, Alhazmi K, Validire P, Louvet C, de Gramont A, Laurent-Puig P, Taieb J and Praz F: ERCC1, XRCC1 and GSTP1 single nucleotide polymorphisms and survival of patients with colon cancer receiving oxaliplatin-based adjuvant chemotherapy. J Cancer 5: 425-432, 2014.
33 Pare L, Marcuello E, Altes A, del Rio E, Sedano L, Salazar J, Cortes A, Barnadas A and Baiget M: Pharmacogenetic prediction of clinical outcome in advanced colorectal cancer patients receiving oxaliplatin/5-fluorouracil as first-line chemotherapy. Br J Cancer 99: 1050-1055, 2008.

34 Spindler KL, Andersen RF, Jensen LH, Ploen J and Jakobsen A: EGF61A $>\mathrm{G}$ polymorphism as predictive marker of clinical outcome to first-line capecitabine and oxaliplatin in metastatic colorectal cancer. Ann Oncol 21: 535-539, 2010.

35 Viguier J, Boige V, Miquel C, Pocard M, Giraudeau B, Sabourin JC, Ducreux M, Sarasin A and Praz F: ERCC1 codon 118 polymorphism is a predictive factor for the tumor response to oxaliplatin/5-fluorouracil combination chemotherapy in patients with advanced colorectal cancer. Clin Cancer Res 11: 62126217,2005 .
Received March 20, 2017

Revised April 4, 2017

Accepted April 6, 2017 